\title{
Study of Eosinophil Count in Nasal and Peripheral Blood Smear Compare with Serum IgE Level in Children with Allergic Rhinitis
}

Khan Md. Shahariar Zaman ${ }^{1}$, Sania Hossain², Suraya Sultana ${ }^{3}$, Shagufta Mehzabeen ${ }^{4}$, Nasrin Jahan ${ }^{5}$, Shaila Yesmin ${ }^{6}$, Sheuly Ferdousi ${ }^{7}$, Debatosh Paul ${ }^{8}$, Mesbah Uddin Ahmed ${ }^{9 *}$, Md. Quddusur Rahman ${ }^{10}$

${ }^{1,5}$ Medical Officer, Department of Laboratory Medicine, Bangabandhu Sheikh Mujib Medical University

${ }^{2}$ Lecturer, Cytopathology, National Institute of Cancer Research and Hospital

${ }^{3}$ Medical Officer, Laboratory Services Division, Sheikh Hasina National Institute of Burn and Plastic Surgery

${ }^{4}$ Medical Officer, Department of Laboratory Medicine, BIRDEM General Hospital, Dhaka

${ }^{6}$ Assistant Professor, Department of Laboratory Medicine, Bangabandhu Sheikh Mujib Medical University

${ }^{7}$ Associate Professor, Department of Laboratory Medicine, Bangabandhu Sheikh Mujib Medical University

${ }^{8}$ Professor and Chairman, Department of Laboratory Medicine, Bangabandhu Sheikh Mujib Medical University

${ }^{9} \mathrm{MS}$ in Microbiology, Bangladesh University of Health Sciences

${ }^{10}$ Professor and Ex-Chairman, Department of Laboratory Medicine, Bangabandhu Sheikh Mujib Medical University

*Corresponding Author: Mesbah Uddin Ahmed, MS in Microbiology, Bangladesh University of Health Sciences.

\section{Received Date: 19 September 2021 | Accepted Date: 14 October 2021 | Published Date: 19 October 2021}

Citation: K Md. S Zaman, S Hossain, S Sultana, S Mehzabeen, Mesbah U Ahmed, et al. (2021) Study of Eosinophil Count in Nasal and Peripheral Blood Smear Compare with Serum IgE Level in Children with Allergic Rhinitis. Journal of Clinical and Laboratory Research. 3(5); DOI: $10.31579 / 2768-0487 / 050$

Copyright: @ 2021 Mesbah Uddin Ahmed. This is an open-access article distributed under the terms of the Creative Commons Attribution License, which permits unrestricted use, distribution, and reproduction in any medium, provided the original author and source are credited.

\begin{abstract}
Introduction: Allergic rhinitis is one of the most common respiratory diseases. Patient with allergic rhinitis may have elevated level of serum IgE and eosinophil than normal person. Nasal smear eosinophil count is a simple test as well as noninvasive, can be repeated and inexpensive method for diagnosis of allergic rhinitis.

Objective: To assess the eosinophil count in nasal smear as an alternative diagnostic test for children with allergic rhinitis.

Methods: This cross-sectional study was conducted at the Department of Laboratory medicine and Paediatrics, BSMMU, Dhaka from September 2019 to August 2020 in 120 children (Age up to 18 years both sex). Diagnosed patients of allergic rhinitis according to ARIA-WHO guideline with history and clinical feature who fulfilled the inclusion criteria were selected as study population. After taking informed written consent blood and nasal secretion of allergic patient were drawn for serum IgE and eosinophil count. Nasal smears for eosinophil were stained using Giemsa stain and observed eosinophil under light microscope. Peripheral blood eosinophil count was estimated by hematology auto-analyzer (SYSMEX-XN 2000) and rechecked manually. The serum total IgE level was performed based on sandwich principle of ELISA.
\end{abstract}

Results: The serum IgE level, nasal smear eosinophil count and blood eosinophil count were found increased with severity of allergic rhinitis, which was statistically significant ( $\mathrm{p}<0.001)$. Pearson's correlation coefficient test revealed significant positive correlation between nasal smear eosinophil count with serum $\operatorname{IgE}(r=+.656, \mathrm{p}<0.001)$ and blood absolute eosinophil count $(\mathrm{r}=+.415, \mathrm{p}<0.001)$.

Conclusion: Nasal smear eosinophil count was significantly raised alone with absolute eosinophil count and serum IgE level with the severity of allergic rhinitis in children.

Keywords: allergic rhinitis; blood absolute eosinophil; serum ige; nasal smear eosinophil 


\section{Introduction}

Allergic rhinitis (AR) is an immunoglobulin $\mathrm{E}(\mathrm{IgE})$ mediated inflammation of the mucous membrane of the nose occurring due to exposure to an inhaled allergen like pollen, dust, mould, fungi and animal dander (Bousquet, Van Cauwenberge \& Khaltaev, 2001). Every person has an experience of one form of allergies in their life time. Allergic rhinitis can begin at any age, but the most common occurrence is during the adolescence or young adulthood. There are no racial or ethical variations (Bakhshaee et al., 2010). Parents suffering from allergic rhinitis have a higher risk of developing allergy for children. Nowadays, it has become a common disease worldwide, affecting a large number of the population. It is estimated that over $20 \%-50 \%$ of the world's population suffer from IgE mediated allergic disease such as rhinitis, asthma, rhinoconjunctivitis, eczema and anaphylaxis (Chowdhury, Kabir \& Alam, 2008). The prevalence of allergic diseases is about $20 \%-25 \%$ in Bangladesh (ISAAC, 2000). The International study of asthma and allergies in childhood (ISAAC) study in the schools of Dhaka has confirmed that the problem of allergic respiratory diseases such as asthma, rhinitis and other atopic conditions are common in child population of our country (Chowdhury, Kabir \& Alam, 2008). In spite of new techniques nasal smear eosinophil count for diagnosis of allergic rhinitis is important for diagnosis and prognosis of allergic rhinitis. The diagnosis of allergic rhinitis is based on a typical history of allergic symptoms and investigation. When two or more symptoms out of sneezing, watery rhinorrhea, nasal obstruction and nasal purities persist for $\geq 1$ hour on most days, allergic rhinitis is strongly suspected. Some diagnostic tests like Skin Prick Test (SPT), Radio-Allergosorbent Test (RAST), estimation of IgE antibodies and Enzyme linked Immunosorbent assay (ELISA) are used for the diagnosis of rhinitis. But these are expensive, complicated, invasive and difficult to collect sample from children. Moreover it may be not possible to perform in peripheral set up (Patel \& Nagpal, 2014). Nasal smear eosinophil count could be a useful test for diagnosis of allergic rhinitis, which is simple, easy to perform, cost effective and would help early diagnosis and to assess patient outcome after treatment. The aim of the present study was designed to evaluate the diagnostic value of nasal smear eosinophil count for allergic rhinitis. The purpose of this study was also to observe the association between nasal smear eosinophil count and peripheral blood eosinophil count and serum total IgE level in allergic rhinitis patients.

\section{Materials and Methods}

Study design: Cross sectional study

Place of study: This study was conducted at the Department of Laboratory medicine and Paediatrics, Bangabandhu Sheikh Mujib Medical University, Dhaka.

Duration of Study Period: September 2019 to August 2020

Study Population: Children with allergic rhinitis attended in Paediatrics OPD of BSMMU.

Sampling method: Purposive sampling

\section{Study Procedure:}

- After ethical clearance from Institutional Review Board (IRB), diagnosed cases of allergic rhinitis attending in outpatient Department of Pediatric, BSMMU, were selected.

- After full explanation regarding the aims, objectives of the study and necessity of the investigations were explained to patients or guardian. Informed written consent was taken from patients or guardian.

- Blood and nasal secretion of allergic patient were drawn for serum IgE and eosinophil count. All tests were done in the Department of Laboratory Medicine, BSMMU.
Sample size: Sample size of patients of allergic rhinitis was 236. But due to pandemic situation based on the availability of patients, ultimately 120 patients among 236 patients were included in this study.

\section{Laboratory Procedure}

Nasal smear preparation: Nasal secretion was collected by asking the child to blow his/her nose into a plastic wrap and then placed on a glass slide. If insufficient secretion is obtained, cotton tipped swab was inserted into a nostril and left for 60 seconds and transferred onto a glass slide. A smear was made and allowed to air dry. The smear was stained using Giemsa stain and observed eosinophil under light microscope. (Murayama \& Murayama, 2018)

Blood sample collection: Blood sample was collected from antecubital vein under asepsis with $0.5 \%$ chlorhexidine gluconate. About $4 \mathrm{ml}$ venous blood was collected into two plastic screw-capped tube. Tube was labeled with the patient's identification number.

Sample processing and storage for IgE: Collected blood sample was kept in upright position for 30 minutes and then centrifuged in 3000 rpm for 5 minutes. After centrifugation, serum sample was separated in Eppendorf tube and marked accordingly. Sample containing Eppendorf tubes were then stored in $-20^{\circ} \mathrm{C}$ temperature and analysis was done in separate occasions.

Peripheral blood smear preparation for eosinophil count: A small drop of blood was placed about 1 or $2 \mathrm{~cm}$ from one end of a precleaned slide and immediately with a pre-cleaned edge was placed at an angle of 45 degrees and moved backwards to make contact with the drop. The drop of blood was spread quickly along the line of contact of spreader with the slide and allowed to air dry. Peripheral blood smear was studied using Leishman's stain. Eosinophil count obtained from CBC which was estimated by hematology auto-analyzer (SYSMEX-XN 2000) using commercially available cartridge in the department of Laboratory Medicine.

Data collection: Data were recorded in a pre-designed, pre tested pro-forma. Patient information was obtained through using patient's information sheet which involves questionnaire, clinical finding and laboratory reports. A semi-structured questionnaire was developed in English. Patients were informed about the purpose of the study and ethical issues. Before proceeding to data collection, the details of the study were explained to each patient and informed verbal and written consent from the respondents was obtained. Data collection procedure was initiated by the researcher himself through face to face interview. From each subject, $4 \mathrm{ml}$ of whole blood was drawn for eosinophil count and serum IgE in blood. Nasal secretion was collected and slide prepared. The serum IgE level was measured by ELISA using sandwich principle. About 18 minutes were taken to collect data from each patient. For this, 1-2 Patients were interviewed each day. After getting reports, the laboratory data was recorded in the data sheet. All data were recorded systematically in a preformed data collection sheet. For all statistical tests we considered $\mathrm{p}$ value $<0.05$ as statistically significant. Statistical analysis was done by using IBM SPSS version 26.0 (SPS Inc. Chicago, II, USA).

\section{Results}

Table 1 shows relationship among severity of allergic rhinitis with serum IgE level. Among 71 intermediate mild type of allergic rhinitis patients $8(11.3 \%)$ patients had serum $\mathrm{IgE}$ level $<100 \mathrm{IU} / \mathrm{ml}$ and among rest of the groups (intermediate moderate, persistent mild and persistent moderate) no patients $(0 \%)$ had serum IgE level <100 IU/ml. Among 71 intermediate mild type of allergic rhinitis patients $21(29.6 \%)$ patients had serum IgE level 100-200 IU/ml. Among rest of the groups (intermediate moderate, persistent mild and persistent moderate) no patients (0\%) had serum IgE level 100-200 IU/ml. Among 71 
intermediate mild type of allergic rhinitis patients $42(59.2 \%)$ patients had serum IgE level >200 IU/ml. Among 19 intermediate moderate type of allergic rhinitis patients $19(100 \%)$ patients had serum IgE level > 200 $\mathrm{IU} / \mathrm{ml}$. Among 4 persistent mild type of allergic rhinitis patients 4 (100\%) patients had serum IgE level $>200 \mathrm{IU} / \mathrm{ml}$. Among 26 persistent moderate type of allergic rhinitis patients $26(100 \%)$ patients had serum IgE level $>200 \mathrm{IU} / \mathrm{ml}$. The test was done by Chi-square test which was found statistically significant ( $\mathrm{p}$ value $<0.001$ ).

\begin{tabular}{|l|c|c|c|c|c|}
\hline Serum IgE level & $\begin{array}{c}\text { Intermediate mild } \\
(\mathbf{n = 7 1 )} \\
\mathbf{N o .}(\boldsymbol{\%})\end{array}$ & $\begin{array}{c}\text { Intermediate } \\
\text { moderate } \\
(\mathbf{n}=\mathbf{1 9}) \\
\mathbf{N o .}(\boldsymbol{\%})\end{array}$ & $\begin{array}{c}\text { Persistent mild } \\
(\mathbf{n = 4}) \\
\mathbf{N o .}(\boldsymbol{\%})\end{array}$ & $\begin{array}{c}\text { Persistent } \\
\text { moderate } \\
(\mathbf{n}=\mathbf{2 6}) \\
\text { No. (\%) }\end{array}$ & p-value \\
\hline$<100$ & $8(11.3 \%)$ & $0(0.0 \%)$ & $0(0.0 \%)$ & $0(0.0 \%)$ & $<0.001 *$ \\
\hline $100-200$ & $21(29.6 \%)$ & $0(0.0 \%)$ & $0(0.0 \%)$ & $0(0.0 \%)$ & \\
\hline$>200$ & $42(59.2 \%)$ & $19(100.0 \%)$ & $4(100.0 \%)$ & $26(100.0 \%)$ & \\
\hline Total & $71(100.0 \%)$ & $19(100.0 \%)$ & $4(100.0 \%)$ & $26(100.0 \%)$ & \\
\hline
\end{tabular}

Chi-square test, *significant

Table 1: Association of severity of allergic rhinitis with serum IgE $(n=120)$

Table 2 shows relationship among severity of allergic rhinitis with blood absolute count. Among 71 intermediate mild type of allergic rhinitis patients $33(46.5 \%)$ patients had blood absolute eosinophil count $<440$ cells $/ \mathrm{mm}^{3}$. Among 19 intermediate moderate type of allergic rhinitis patients $6(31.6 \%)$ patients had blood absolute eosinophil count $<440$ cells $/ \mathrm{mm}^{3}$. Among 4 persistent mild type of allergic rhinitis patients 0 $(0 \%)$ patients had blood absolute eosinophil count $<440$ cells $/ \mathrm{mm}^{3}$. Among 26 persistent moderate type of allergic rhinitis patients $2(7.7 \%)$ patients had blood absolute eosinophil count $<440 \mathrm{cells} / \mathrm{mm}^{3}$. Among 71 intermediate mild type of allergic rhinitis patients $38(53.5 \%)$ patients had blood absolute eosinophil count $>440$ cells $/ \mathrm{mm}^{3}$. Among 19 intermediate moderate type of allergic rhinitis patients $13(68.4 \%)$ patients had blood absolute eosinophil count $>440$ cells $/ \mathrm{mm}^{3}$. Among 4 persistent mild type of allergic rhinitis patients $4(100 \%)$ patients had blood absolute eosinophil count $>440$ cells $/ \mathrm{mm}^{3}$. Among 26 persistent moderate type of allergic rhinitis patients $24(92.3 \%)$ patients had blood absolute eosinophil count $>440$ cells $/ \mathrm{mm}^{3}$. The test was done by Chi-square test which was found statistically significant ( $\mathrm{p}$ value is 0.002 ).

\begin{tabular}{|c|c|c|c|c|c|}
\hline $\begin{array}{l}\text { Absolute blood } \\
\text { eosinophil count }\end{array}$ & $\begin{array}{l}\text { Intermediate } \\
\text { mild } \\
(n=71) \\
\text { No. }(\%)\end{array}$ & $\begin{array}{c}\text { Intermediate } \\
\text { moderate } \\
(n=19) \\
\text { No. }(\%)\end{array}$ & $\begin{array}{c}\text { Persistent mild } \\
(n=4) \\
\text { No. }(\%)\end{array}$ & $\begin{array}{c}\text { Persistent } \\
\text { moderate } \\
(\mathbf{n}=26) \\
\text { No. }(\%)\end{array}$ & p-value \\
\hline$<440$ & $33(46.5 \%)$ & $6(31.6 \%)$ & $0(0.0 \%)$ & $2(7.7 \%)$ & \multirow{2}{*}{$0.002 *$} \\
\hline$>440$ & $38(53.5 \%)$ & $13(68.4 \%)$ & $4(100.0 \%)$ & $24(92.3 \%)$ & \\
\hline Total & $71(100.0 \%)$ & $19(100.0 \%)$ & $4(100.0 \%)$ & $26(100.0 \%)$ & \\
\hline
\end{tabular}

Chi-square test, *significant

Table 2: Association of severity of allergic rhinitis with blood absolute eosinophil count $(n=120)$

Table 3 shows relationship among severity of allergic rhinitis with nasal smear eosinophil count. Among 71 intermediate mild type of allergic rhinitis patients $58(81.7 \%)$ patients had positive nasal smear eosinophil count. Among 19 intermediate moderate type of allergic rhinitis patients $18(94.7 \%)$ patients had positive nasal smear eosinophil count. Among 4 persistent mild type of allergic rhinitis patients $4(100 \%)$ patients had positive nasal smear eosinophil count. Among 26 persistent moderate type of allergic rhinitis patients $26(100.0 \%)$ patients had positive nasal smear eosinophil count. Among 71 intermediate mild type of allergic rhinitis patients $13(18.3 \%)$ patients had negative nasal smear eosinophil count. Among 19 intermediate moderate type of allergic rhinitis patients $1(5.3 \%)$ patients had negative nasal smear eosinophil count. Among 4 persistent mild type of allergic rhinitis patients $4(100 \%)$ patients had positive nasal smear eosinophil count. Among 26 persistent moderate type of allergic rhinitis patients $0(0.0 \%)$ patients had negative nasal smear eosinophil count. The test was done by Chi-square test which was found statistically significant ( $\mathrm{p}$ value $=0.051$ ).

\begin{tabular}{|l|c|c|c|c|c|}
\hline $\begin{array}{l}\text { Nasal smear } \\
\text { eosinophil } \\
\text { severity }\end{array}$ & $\begin{array}{c}\text { Intermediate mild } \\
(\mathbf{n}=\mathbf{7 1}) \\
\text { No. }(\%)\end{array}$ & $\begin{array}{c}\text { Intermediate } \\
\text { moderate } \\
(\mathbf{n = 1 9 )} \\
\mathbf{N o .}(\%)\end{array}$ & $\begin{array}{c}\text { Persistent mild } \\
(\mathbf{n}=\mathbf{4}) \\
\text { No. }(\%)\end{array}$ & $\begin{array}{c}\text { Persistent } \\
\text { moderate } \\
(\mathbf{n = 2 6}) \\
\text { No. }(\%)\end{array}$ & p-value \\
\hline Positive & $58(81.7 \%)$ & $18(94.7 \%)$ & $4(100.0 \%)$ & $26(100.0 \%)$ & \multirow{2}{*}{$0.051^{*}$} \\
\hline Negative & $13(18.3 \%)$ & $1(5.3 \%)$ & $0(0.0 \%)$ & $0(0.0 \%)$ & \\
\hline Total & $71(100.0 \%)$ & $19(100.0 \%)$ & $4(100.0 \%)$ & $26(100.0 \%)$ & \\
\hline
\end{tabular}

Chi-square test, *significant

Table 3: Association of severity of allergic rhinitis with nasal smear eosinophil count $(n=120)$ 
Table 4 shows the mean serum IgE level in intermediate mild type of allergic rhinitis patients is $206.1 \pm 74.3 \mathrm{IU} / \mathrm{ml}$. The mean serum IgE level in intermediate moderate type of allergic rhinitis patients is $334.7 \pm 119.2$ $\mathrm{IU} / \mathrm{ml}$. The mean serum IgE level in persistent mild type of allergic rhinitis patients is $335.0 \pm 75.9 \mathrm{IU} / \mathrm{ml}$ and the mean serum IgE level in persistent moderate type of allergic rhinitis patients is $515.8 \pm 162 \mathrm{IU} / \mathrm{ml}$. The $\mathrm{p}$-value is $<0.001$ which is statistically significant. The mean blood eosinophil count in intermediate mild type of allergic rhinitis patients is 472.0 \pm 201.5 . The mean blood eosinophil count in intermediate moderate type of allergic rhinitis patients is $547.6 \pm 176.4$. The mean blood eosinophil count in persistent mild type of allergic rhinitis patients is $732.5 \pm 77.9$ and the mean blood eosinophil count in persistent moderate type of allergic rhinitis patient's is $880.1 \pm 306.4$. The $p$-value is $<0.001$ which is statistically significant. In this table we also shows relationship among severity of allergic rhinitis with nasal smear eosinophil count was done. Among 71 intermediate mild type of allergic rhinitis patients $58(81.7 \%)$ patients had positive nasal smear eosinophil count. Followed by $18(94.7 \%)$ patients intermediate moderate type, and $100.0 \%$ persistent mild and persistent moderate type of allergic rhinitis patients had positive nasal smear eosinophil count. $P$ value was 0.051 which was statistically significant. The serum IgE level, blood eosinophil count and nasal smear eosinophil count were increased with severity of allergic rhinitis.

\begin{tabular}{|l|l|l|l|l|l|}
\hline Variables & $\begin{array}{c}\text { Intermediate mild } \\
(\mathbf{n}=\mathbf{7 1}) \\
\text { Mean } \pm \text { SD }\end{array}$ & $\begin{array}{c}\text { Intermediate } \\
\text { moderate } \\
(\mathbf{n}=\mathbf{1 9}) \\
\text { Mean } \pm \text { SD }\end{array}$ & $\begin{array}{c}\text { Persistent mild } \\
(\mathbf{n}=\mathbf{4}) \\
\text { Mean } \pm \text { SD }\end{array}$ & $\begin{array}{c}\text { Persistent } \\
\text { moderate } \\
(\mathbf{n}=\mathbf{2 6}) \\
\text { Mean } \pm \text { SD }\end{array}$ & p-value \\
\hline Serum IgE level & $206.1 \pm 74.3$ & $334.7 \pm 119.2$ & $335.0 \pm 75.9$ & $515.8 \pm 162.0$ & $<0.001 *$ \\
\hline Blood eosinophil count & $472.0 \pm 201.5$ & $547.6 \pm 176.4$ & $732.5 \pm 77.9$ & $880.1 \pm 306.4$ & $<0.001 *$ \\
\hline $\begin{array}{l}\text { Nasal smear eosinophil } \\
\text { count }\end{array}$ & $58(81.7 \%)$ & $18(94.7 \%)$ & $4(100.0 \%)$ & $26(100.0 \%)$ & $0.051 *$ \\
\hline
\end{tabular}

ANOVA test, Chi-square test *significant

Table 4: Comparison of serum IgE level, blood eosinophil count and nasal smear eosinophil count between intermittent and persistent allergic rhinitis $(n=120)$

Table 5 shows comparison of serum IgE and nasal smear eosinophil count with severity of disease. Among 120 study patients 106 children had positive nasal smear eosinophil that is $\geq 10$ eosinophil/hpf. Here mean serum IgE level is $311.5 \pm 167$. Among 120 study patients 14 children had negative nasal smear eosinophil that is $<10$ eosinophil/hpf. Here mean serum IgE level is $194.6 \pm 65$. The difference is statistically significant (pvalue 0.011 )

\begin{tabular}{|c|c|c|c|}
\hline \multirow{2}{*}{} & \multicolumn{2}{|c|}{ Nasal smear eosinophil count with severity } & \multirow{2}{*}{ p-value } \\
\cline { 2 - 3 } & $\begin{array}{c}\text { Positive } \\
(\mathrm{n}=106) \\
\text { Mean } \pm \mathrm{SD}\end{array}$ & $\begin{array}{c}\text { Negative } \\
(\mathrm{n}=14) \\
\text { Mean } \pm \mathrm{SD}\end{array}$ & \\
\hline Serum IgE & $311.5 \pm 167.7$ & $194.6 \pm 65.6$ & $0.011^{*}$ \\
\hline
\end{tabular}

Unpaired t-test was done, *significant

Table 5: Relation of Serum Ig E and nasal smear eosinophil count with severity of the study population

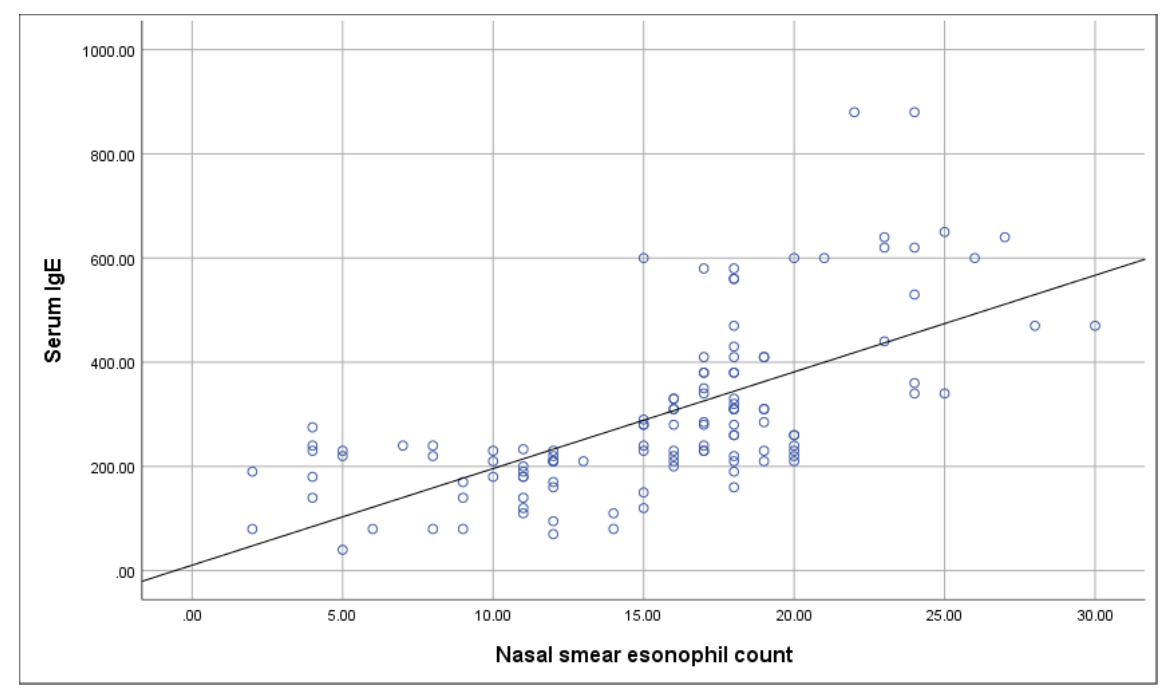

Figure 1: showed the correlation between nasal smear eosinophil count with serum $\operatorname{IgE}(r=+.656, p<0.001)$. Pearson's correlation test was done that shows the strong positive correlation of nasal smear eosinophil count with serum IgE. 


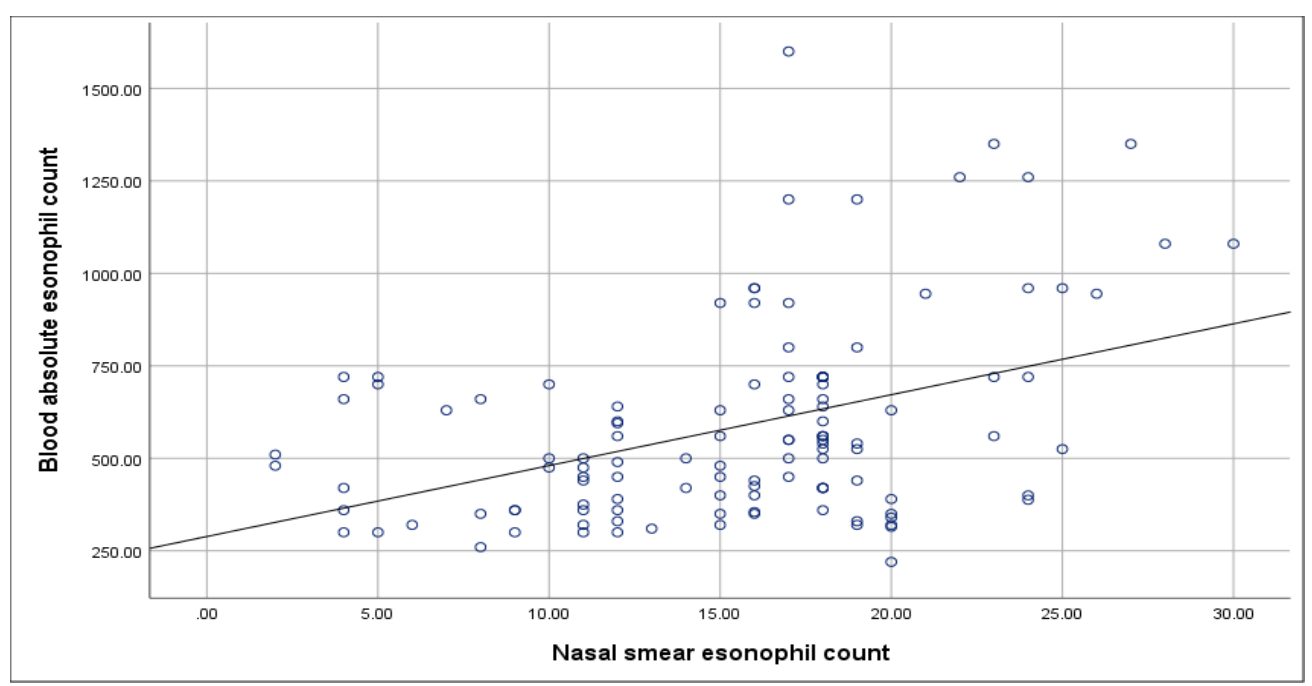

Figure 2: showed the correlation between nasal smear eosinophil count with blood absolute eosinophil count $(r=+.415, p<0.001)$. Pearson's correlation test was done that shows the significant moderate positive of nasal smear eosinophil count with blood absolute eo sinophil count.

\section{Discussion}

Allergic rhinitis is one of the most common disorders of upper respiratory tract. Several biomarkers associated with allergic rhinitis have been the subject of research in last few decades. Nasal eosinophil provides valuable and timely diagnostic information for allergic rhinitis. Accumulation of eosinophil granulocytes is a characteristic feature of allergic diseases. It plays a pathogenic role in allergic disorders. During allergen challenge, eosinophils increase in number and release mediators. Therefore, there is a possible relation between nasal smear eosinophil count with allergic rhinitis. This study aimed to evaluate the nasal smear eosinophil count as an alternative diagnostic in children with allergic rhinitis. In this study it was compared eosinophil count in nasal smear, peripheral blood smears and serum IgE level in children with different types of allergic rhinitis patient. Total 120 patients attending in the outpatient department of Paediatrics in BSMMU were included. This study showed the relationship among severity of allergic rhinitis with different level of serum IgE, which was found statistically significant. Meena et al. (2016) found mean serum IgE level of children having persistent allergic rhinitis were significantly higher than children having intermediate allergic rhinitis. Ciprandi et al. (2010) also found serum IgE concentration significantly differed among the different group of allergic rhinitis patients. These findings are also relevant with the findings of current study. In this present study, it was found a significant relationship among the severity of allergic rhinitis with different levels of blood eosinophil count which was statistically significant. Lee et al. (2008) found blood eosinophil count was higher in the persistent group than in the intermediate group. This finding is consistent with the findings of the current study. In this study, the association of severity of allergic rhinitis with nasal smear eosinophil count was assessed. Among 120 study patient, 71 intermediate mild 58(81.7\%) patients had positive nasal smear eosinophil and 13 (18.3\%) patients had negative nasal smear eosinophil. Besides, 19 patients had intermediate moderate type of allergic rhinitis, $18(94.7 \%)$ patients had positive nasal smear eosinophil and only $1(5.3 \%)$ patients had negative nasal smear eosinophil. Among 120 study patients, $100 \%$ persistent mild and persistent moderate type of allergic had positive nasal smear eosinophil. The p-value is 0.051 which was statistically significant. Patel \& Nagpal. (2014) have found that $8.57 \%$ patients out of 70 patients had negative nasal smear, whereas $64(91.43 \%)$ patients had a positive smear for eosinophils. There was a good correlation of nasal smear eosinophil with severity of clinical score. These findings are nearly consistent with the findings of current study. In this present study, the comparison of serum IgE and blood eosinophil and nasal smear eosinophil count between intermittent and persistent allergic rhinitis was done. It was found that serum IgE level is significantly increased with the severity in children with allergic rhinitis. It is statistically significant. Corsico et al. (2017) have found that serum IgE level is significantly increased with severity of allergic rhinitis in children. Ciprandi et al. (2010) also have found that serum $\operatorname{lgE}$ concentration significantly differed among the different group of allergic rhinitis patients, which is statistically significant. This study showed that blood eosinophil count is significantly increased with the severity in children with allergic rhinitis, which is statistically significant. Blood eosinophil count increased with severity of allergic rhinitis. Children with allergic rhinitis had significant blood eosinophil count. Lee et al. (2008) found that there was a statistically significant difference of the blood eosinophil count among the 4 groups (Intermediate mild, Intermediate moderate, Persistence mild and Persistence moderate) of allergic rhinitis patients. Nasal smear eosinophil count increase alone with severity of rhinitis. Patel \& Nagpal. (2014) had found $(91.43 \%)$ patients had a positive smear for eosinophils. There was a good correlation of nasal smear eosinophil with severity of clinical score. These findings are nearly consistent with the findings of current study. Pearson's correlation coefficient test was done in order to assess the correlation between nasal smear eosinophil count with serum IgE. In the present shows the strong positive correlation of nasal smear eosinophil count with serum IgE. Pearson's correlation coefficient test also assess the correlation between nasal smear eosinophil count with blood absolute eosinophil count. In the present study showed a moderate significant correlation of nasal smear eosinophil count with blood absolute eosinophil count. No such study was done to see the correlation between nasal smear eosinophil count with blood absolute eosinophil count and serum IgE. From the current study results, the nasal eosinophilia might be a contributing factor to the diagnosis of allergic rhinitis as compared to blood eosinophilia. It may help the physicians as an additional tool for diagnosed allergic rhinitis. It is a simple test for clinical use, which can be done in a small set up with minimal laboratory facilities. As blood collection from children is an invasive and complicated procedure, in that case nasal smear eosinophil count is an easy procedure. Therefore, measurement of nasal smear eosinophil in allergic rhinitis patients is a simple, cost effective and reproducible marker which can be easily determined.

\section{Conclusion}

Nasal eosinophil count contributes in diagnosis of allergic rhinitis. Nasal smear eosinophil count was significantly raised alone with absolute 
eosinophil count and serum IgE level with the severity of allergic rhinitis in children. So nasal smear eosinophil count is a simple, non-invasive, economical and reliable test that can be used as an alternative tool to diagnose allergic rhinitis in children.

\section{References}

1. Bousquet, J, Van Cauwenberge P and Khaltaev N. (2001). Allergic rhinitis and its impact on asthma. Journal of allergy and clinical immunology. 108(5):147-334.

2. Bakhshaee M, Fereidouni M, Farzadnia M and Varasteh A.R. (2010). The nasal smear for eosinophils, its value, and its relation to nasal mucosal eosinophilia in allergic rhinitis. Iranian Journal of Otorhinolaryngology. 22(3): 73-78.

3. Ciprandi G, De Amici M, Giunta V and Marseglia G.L. (2010). Comparison of serum specific IgE and skin prick test in polysensitized patients. International Journal of Immunopathology and Pharmacology. 23(4):1293-1295.

4. Corsico A.G, De Amici M, Ronzoni V, Giunta V, Mennitti M.C, Viscardi A, Marseglia G.L. and Ciprandi G. (2017). Allergen-specific immunoglobulin $\mathrm{E}$ and allergic rhinitis severity. Allergy \& Rhinology (Providence, RI). 8(1):1-4.
5. Chowdhury M.., Kabir, A.R.M.L and Alam. M., (2008). 'Allergic rhinitis, asthma and atopic diseases: Bangladesh perspective', Bangladesh Journal of Othorhinolaryngology. 14(2): 66-70.

6. Lee C.H, Jang J.H, Lee H.J, Kim I.T, Chu M.J, Kim C.D, Won Y.S and Kim J.W. 2008. Clinical characteristics of allergic rhinitis according to allergic rhinitis and its impact on asthma guidelines. Clinical and experimental otorhinolaryngology. 1(4):196-200.

7. Murayama N. and Murayama K. (2018). Nasal Discharge Eosinophils in Childhood Asthma Patients as a Predictive Factor for Persistent Asthma. Mediators of inflammation. 2563978-2563978.

8. Meena C, Poddar M, Sharma B.S, Devpura K and Meena M. (2016). Estimation of serum immunoglobulin E levels as suggestive indicator of atopy in children having allergic rhinitis. Indian Journal of Allergy, Asthma and Immunology. 30(1):17.

9. Patel A.K. and Nagpal T.P. (2014). Comparison of blood absolute eosinophil count and nasal smear eosinophils with symptoms and severity of clinical score in patients of allergic rhinitis. Indian Journal of Allergy, Asthma and Immunology. 28(2):74.
This work is licensed under Creative Commons Attribution 4.0 License

To Submit Your Article Click Here: Submit Manuscript

DOI: $10.31579 / 2768-0487 / 050$
Ready to submit your research? Choose Auctores and benefit from:

$>$ fast, convenient online submission

$>$ rigorous peer review by experienced research in your field

$>$ rapid publication on acceptance

$>$ authors retain copyrights

$>$ unique DOI for all articles

> immediate, unrestricted online access

At Auctores, research is always in progress.

Learn more auctoresonline.org/journals/journal-of-clinical-andlaboratory-research 